\title{
Desenvolvimento de um Jogo para Apoio de Ensino a Ciências: Um Estudo de Caso
}

\author{
Rodrigo A. S. Alves ${ }^{1}$, Raquel O. Prates ${ }^{1}$, Elaine S. França ${ }^{2}$ \\ ${ }^{1}$ Departamento de Ciência da Computação - Universidade Federal de Minas Gerais \\ (UFMG) - Belo Horizonte, MG - Brazil \\ ${ }^{2}$ Centro Pedagógico / Escola de Educação Básica e Profissional - Universidade Federal \\ de Minas Gerais (UFMG) - Belo Horizonte, MG - Brazil \\ \{rsa, rprates\} @dcc.ufmg.br, lainesf@yahoo.com
}

\begin{abstract}
This paper presents the experience in the development and evaluation in real context of a game aimed at the support to teaching science, specifically Brazilian biomes, in elementary school. Although initial results do not indicate that the game increases students' learning, benefits related to their motivation and interest have been identified as positive outcomes.
\end{abstract}

Resumo. Este artigo apresenta a experiência vivenciada no desenvolvimento e avaliação em contexto real de um jogo voltado ao apoio do Ensino de Ciências, especificamente biomas brasileiros, no Ensino Fundamental. Embora a avaliação inicial do jogo não tenha gerado indicadores de que ele melhora o desempenho no aprendizado do alunos, foram identificados benefícios relativos à motivação e interesse dos alunos.

\section{Introdução}

Atualmente, diversas tecnologias vêm sendo desenvolvidas para auxiliar o ensino nos mais diversos níveis, seja com o intuito de auxiliar as atividades desenvolvidas pelo professor, seja para apoiar o entendimento dos conteúdos pelos alunos [Pietruchinski et al,2012]. O presente trabalho se propõe a desenvolver e analisar um jogo de computador de apoio ao Ensino de Ciências voltado para o Ensino Fundamental. O tema central deste software são os principais biomas brasileiros e suas características.

Atividades como estas, que diferem do cotidiano didático padrão, têm levantado bastante interesse por parte dos alunos, culminando assim em um maior engajamento, $o$ que, de fato, possibilita bons resultados como pode ser observado em [Silva et al, 2010] e [Calisto et al, 2010]. Assim, o investimento em jogos educacionais que possam ser utilizados como recursos no Ensino Fundamental pode trazer melhorias para o ensino e aprendizagem no contexto brasileiro.

A geração de jogos digitais que envolvam conteúdos sendo trabalhados em sala de aula requer a integração de conhecimentos de áreas diferentes o que nem sempre é uma tarefa trivial, por envolver profissionais com visões e metodologias de trabalho heterogêneas. No caso do trabalho apresentado neste artigo, os profissionais envolvidos eram das áreas de computação e biologia. Com o objetivo de facilitar o processo de comunicação relativo ao jogo foram utilizadas técnicas específicas de desenvolvimento 
que poderiam facilitar a geração de um entendimento e linguagem comum sobre o projeto.

Embora as técnicas não tenham correspondido às expectativas o objetivo de gerar um jogo que pudesse auxiliar no ensino de conteúdo de Ciências foi alcançado. Neste artigo foram discutidos brevemente os desafios vivenciados, apresentando o jogo desenvolvido e a avaliação preliminar realizada em sala de aula com os alunos. $\mathrm{O}$ trabalho obteve como resultado indicadores positivos sobre o uso desta tecnologia em sala de aula.

Na próxima seção serão apresentados os trabalhos relacionados com o jogo desenvolvido neste artigo. $\mathrm{Na}$ seção 3, é exposta a metodologia adotada no desenvolvimento do jogo, seguida da descrição do jogo implementado. É, então, apresentada a avaliação preliminar e a discussão dos resultados obtidos. Finalmente, o artigo trata das considerações finais.

\section{Trabalhos Relacionados}

Recentemente foi feito um levantamento a respeito dos trabalhos publicados no SBIE relacionados a jogos aplicados em contextos educacionais [Pietruchinski et al, 2011]. Neste levantamento, os autores mostram que este tema é tratado em 5,4\% das publicações do SBIE, considerando o período entre 2001 e 2010. Entretanto, a maioria destes trabalhos estão ligados ao ensino de Ciência da Computação. Apesar da área de Ensino de Ciências e Matemática obter certa representatividade, o foco principal dos artigos está ligado aos níveis de Ensino Médio e Ensino Superior.Um exemplo de jogo educacional cujo foco é o Ensino de Ciências está descrito em [Loula et al, 2009]. O software Calango busca apoiar o ensino de ecologia através de um ambiente virtual, dotado de certo realismo, a fim de proporcionar aos alunos a compreensão de processos ecológicos e evolutivos. Contudo, até pela própria característica do evento no qual foi publicado, o SBGames, o artigo foca mais na discussão das funcionalidades e requisitos de desenvolvimento, do que no uso do jogo em sala de aula.

Outro jogo educacional voltado para o Ensino Fundamental é A Fazenda [Silva e Passerino, 2007]. A Fazenda tem o objetivo de ensinar conceitos de um meio ambiente sustentável, através de simulação de uma fazenda a ser gerenciada pelo aluno. O jogo permite ao professor trabalhar com os alunos conteúdos interdisciplinares. No artigo, embora os autores digam que o sistema tenha sido avaliado em sala de aula, não descrevem a experiência desta avaliação.

Além dos jogos voltados para algum conteúdo de Ciências, outros permitem que se customize o jogo para diferentes conteúdos. Por exemplo, em [Neves e Giraffa 2007] é apresentado um jogo da memória customizável, em que os professores podem entrar as imagens que vão compor as peças da memória. Assim, os professores poderiam utilizar o jogo de memória como ferramenta de apoio complementar a diversos conteúdos trabalhados em sala de aula.

Além dos jogos que permitem tratar questões relacionadas a Ciências, identificamos vários jogo voltados a outros conteúdos do Ensino Fundamental I e II. Por exemplo, o Robô Poeta [de Paula e Paim, 2009] visa possibilitar ao aluno aprendizagem de poesias através da construção colaborativa de poemas. Já [Lima, 2010] propõe a criação de um jogo RPG (Role-Playing Game) em que seja possível simular a vivência 
em um país estrangeiro e, com isto, estudar o idioma. Ao discutir a respeito da relevância de jogos computacionais, no contexto do Ensino Fundamental, [Silva e Morais 2011] apresentam exemplos de jogos simples de tabuleiro e tabuada aplicados no sentido de apoio à educação nas áreas de língua portuguesa e matemática.

Ao analisarmos os trabalhos relacionados, verificamos que o uso de jogos no ensino tem se mostrado uma direção promissora [Kessler et al, 2010]. No entanto, foram encontradas poucas pesquisas relaciodas tanto do desenvolvimento de jogos focalizados em apoiar o Ensino da área de Ciências voltada para o conteúdo de biologia do Ensino Fundamental, quanto do uso de jogos em sala de aula, de jogos. Assim, este artigo contribui para os esforços nesta direção apresentando a experiência obtida no desenvolvimento de um jogo voltado para o conteúdo de Ciências e sua avaliação inicial em sala de aula.

\section{Metodologia}

A equipe de desenvolvimento deste projeto era composta por três pessoas: 1) uma professora de Ciências do Ensino Fundamental I e II; 2) uma professora de Ciência da IComputação; 3) um aluno de Sistemas de Informação. $O$ objetivo era o desenvolvimento de um jogo que pudesse ser utilizado no Ensino de Ciências para crianças na faixa de 10 a 12 anos ( $5^{\circ}$ e $6^{\circ}$ ano do Ensino Fundamental).

O primeiro passo no processo foi a definição do conteúdo a ser abordado, em função das necessidades pedagógicas das turmas de Ensino Fundamental que utilizariam o jogo. Foi levado em consideração as possibilidades tecnológicas de desenvolvimento e as limitações geradas pela tecnologia disponibilizada na escola para seu uso pelos alunos. Decidiu-se que seria um jogo voltado para o ensino de "Biomas Brasileiros e suas características". O objetivo inicial era que o jogo fosse customizável de forma que o professor pudesse definir diferentes focos em relação ao conteúdo, como, por exemplo trabalhar apenas o impacto de diferentes solos no bioma.

Para apoiar a modelagem do sistema pela equipe, decidiu-se pelo uso Modelo de Representação de Apoio ao Aprendizado (MRA)[Prates e Figueiredo, 2005]. Este modelo permite que se defina as tarefas a serem realizadas pelo aluno no software e para cada uma delas os scaffolds (ou apoio ao aprendizado) a serem oferecidos aos alunos. Assim, a ideia era que as tarefas seriam modeladas pelos membros com formação em computação, e que a professora geraria a descrição dos apoios para cada tarefa ou ação a ser realizada pelo aluno.

No entanto, neste estudo, o MRA não se mostrou suficiente como artefato de comunicação ou integração para o professor de Ciências e desenvolvedores, pois por ser um modelo ainda bastante abstrato do sistema a ser desenvolvido requeria um conhecimento de modelagem de sistemas para se antever o que significavam decisões no modelo para o sistema a ser gerado. Assim, decidiu-se que seria mais produtivo um desenvolvimento baseado em protótipos, no qual o protótipo seria a base para a discussão de questões definidas ou por definir relativas ao jogo. Desta forma, à modelagem das tarefas anteriormente elaborada foi acrescida a modelagem da interação, utilizando o modelo MoLIC [Silva e Barbosa, 2007]. Finalmente, foi criado um protótipo inicial, que serviu de subsídio para a continuação do processo. 
A partir do desenvolvimento do primeiro protótipo a equipe se reuniu com frequência para modificá-lo ou incrementá-lo a fim de gerar uma versão final, pronta para ser utilizada em um primeiro teste com o usuário. Neste processo, houve ainda dificuldade em se definir o quê e como deveria ser customizado pelo professor. Os membros com formação em tecnologia tinham dificuldade em antever que aspectos poderiam ser interessantes em termos didáticos de serem customizados pelo professor. Os membros com formação em biologia tinham dificuldade em antever que parâmetros do sistema deveriam ser definidos para customização. Assim, decidiu-se por criar uma primeira instância do jogo que não fosse customizável, mas que permitiria a avaliação com os alunos e uma análise melhor de que tipo de customização poderia ser interessante em termos didáticos.

É importante destacar que o jogo foi desenvolvido para que fosse usado pelo professor como ferramenta de complementar à bibliografia adotada. Além disso, inicialmente o foco era no seu uso em um laboratório de informática na escola, permitindo ao professor um maior controle de sua utilização e, possivelmente melhor resultado no ensino dos alunos.

\section{Descrição do Jogo}

Como resultado, foi desenvolvido um jogo computacional na linguagem Java, com o paradigma de orientação por objeto. Esta linguagem é justificada por ser gratuita, muito utilizada e por ser interpretada o que, neste caso, a torna multiplataforma. Este último quesito é essencial, uma vez que em diversas escolas vêm sendo adotadas tecnologias de software livre por haver incentivo governamental. No entanto, não podemos deixar de considerar que em muitos ambientes o Microsoft Windows é bastante consolidado.

Inicialmente, acreditávamos que um desenvolvimento de um sistema executado na internet seria mais adequado às necessidades dos possíveis usuários. Entretanto, devido ao uso da internet ser um requisito a mais que impossibilitaria sua aplicação com ausência de conexão e de fatores que dificultariam o desenvolvimento WEB da mesma, optamos por uma versão desktop compatível com os sistemas operacionais mais populares, desde que em suas últimas versões e com máquina virtual JAVA instalada.

O jogo propõe ao aluno uma situação em que seu objetivo é fazer o reflorestamento de um determinado bioma em uma área da cidade. Para isso, o aluno tinha recursos - tempo e dinheiro - que podem se esgotar se não tomar boas decisões sobre o processo de reflorestamento. Para conseguir reflorestar a área o aluno deve tomar decisões adequadas em relação ao tipo de solo, quantidade de água, exposição à luz e temperatura necessários para o bioma em questão.

Ao iniciar o jogo o estudante escolhe qual bioma ele usará no reflorestamento e é então informado do seu desafio: ele deverá ser capaz de reflorestar uma determinada área nativa do bioma escolhido. $\mathrm{O}$ estudante deve então escolher características (solo, a quantidade de água, a exposição à luz e a temperatura) que pretende usar no seu reflorestamento. Uma vez feito isso, ele deve clicar em "Avançar" para simular a passagem do tempo e ver os efeitos das suas decisões na área. A Figura 1 mostra a tela principal do jogo: 


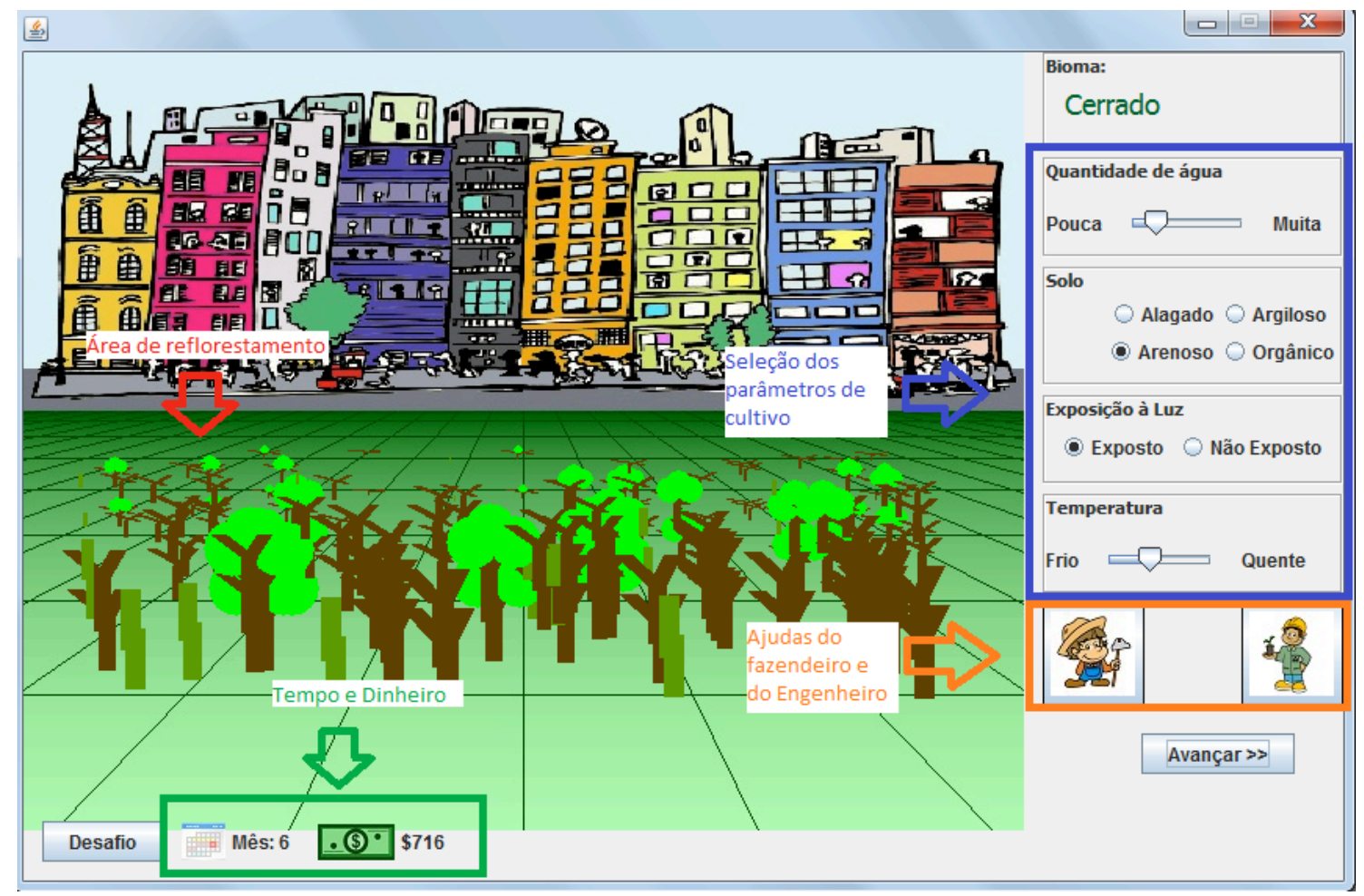

Figura 1. Tela principal do jogo

O tempo do jogo é baseado em semanas e o aluno tem à sua disposição um valor em dinheiro destinado pela prefeitura da cidade para o reflorestamento. O objetivo é reflorestar com maior eficiência, ou seja, com menos tempo e menor quantidade de dinheiro utilizados. Tanto a limitação financeira, quanto a temporal, inseridas no jogo, tiveram como objetivo fornecer aos alunos um indicador de desempenho que os mesmos pudessem avaliar e, ao mesmo tempo, incentivá-los a conseguir resultados cada vez melhores.

À medida que o aluno avança no tempo, ele recebe uma mensagem sobre seu desempenho e tem à sua disposição um fazendeiro e um engenheiro ambiental que podem lhe ajudar a ajustar os parâmetros de reflorestamento, caso seja necessário. $\mathrm{O}$ fazendeiro oferece dicas mais gerais e o valor pago pela sua ajuda é menor. A dica do fazendeiro sempre se refere ao parâmetro, dentre os quatro, que tenha sido a pior escolha do jogador até o momento (Figura 2).

Já o engenheiro ambiental esclarece uma dúvida mais específica a respeito de um determinado parâmetro, informando se a escolha é adequada ou se deve ser efetuada a troca do valor escolhido. A sequência de passos deste apoio pode ser vista na Figura 3.Por ser mais específica, esta dica foi considerada mais cara. A cada semana o jogador só poderá pedir um auxílio a cada um dos personagens citado, anteriormente. 


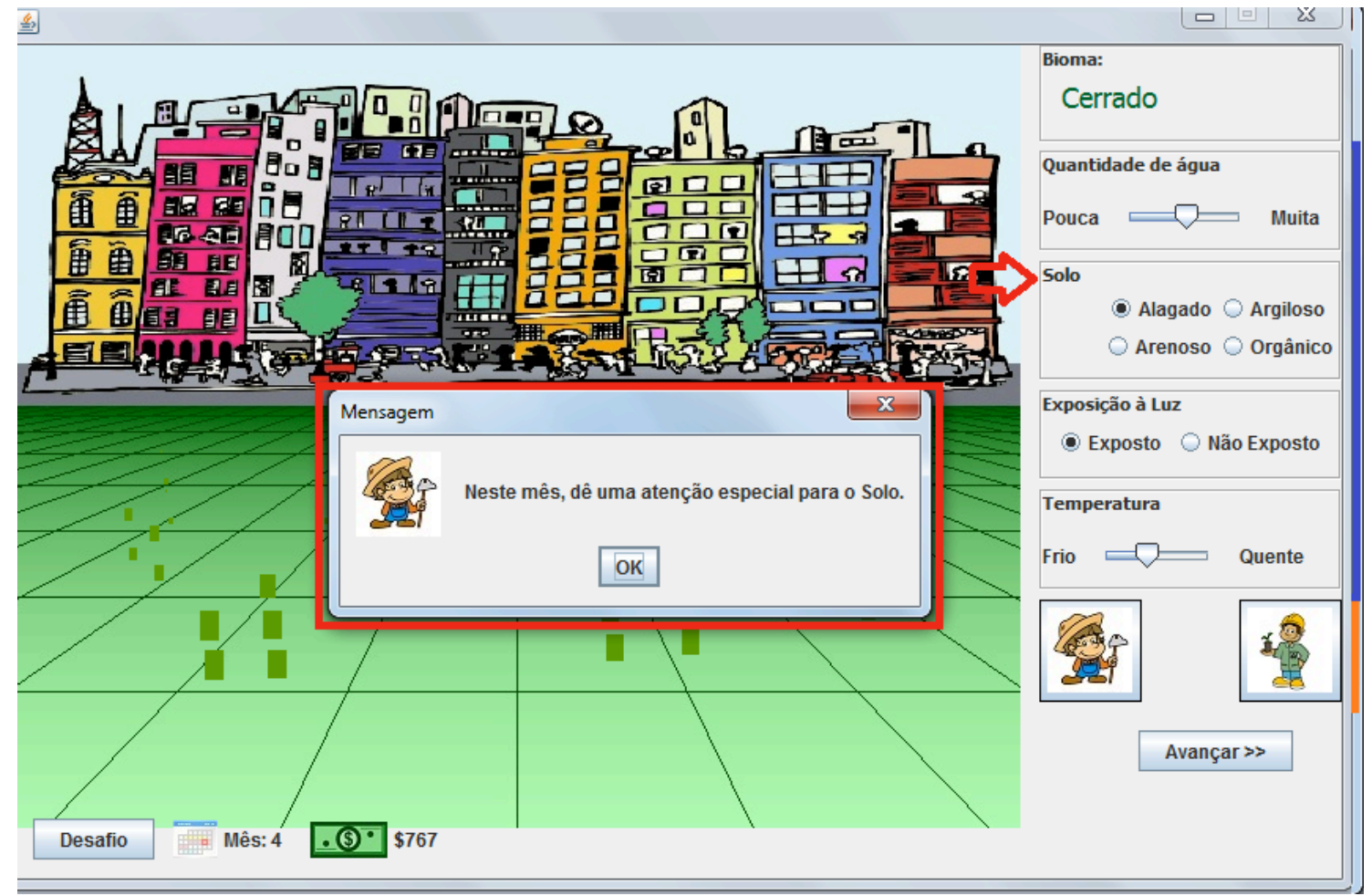

Figura 2. Dica do fazendeiro

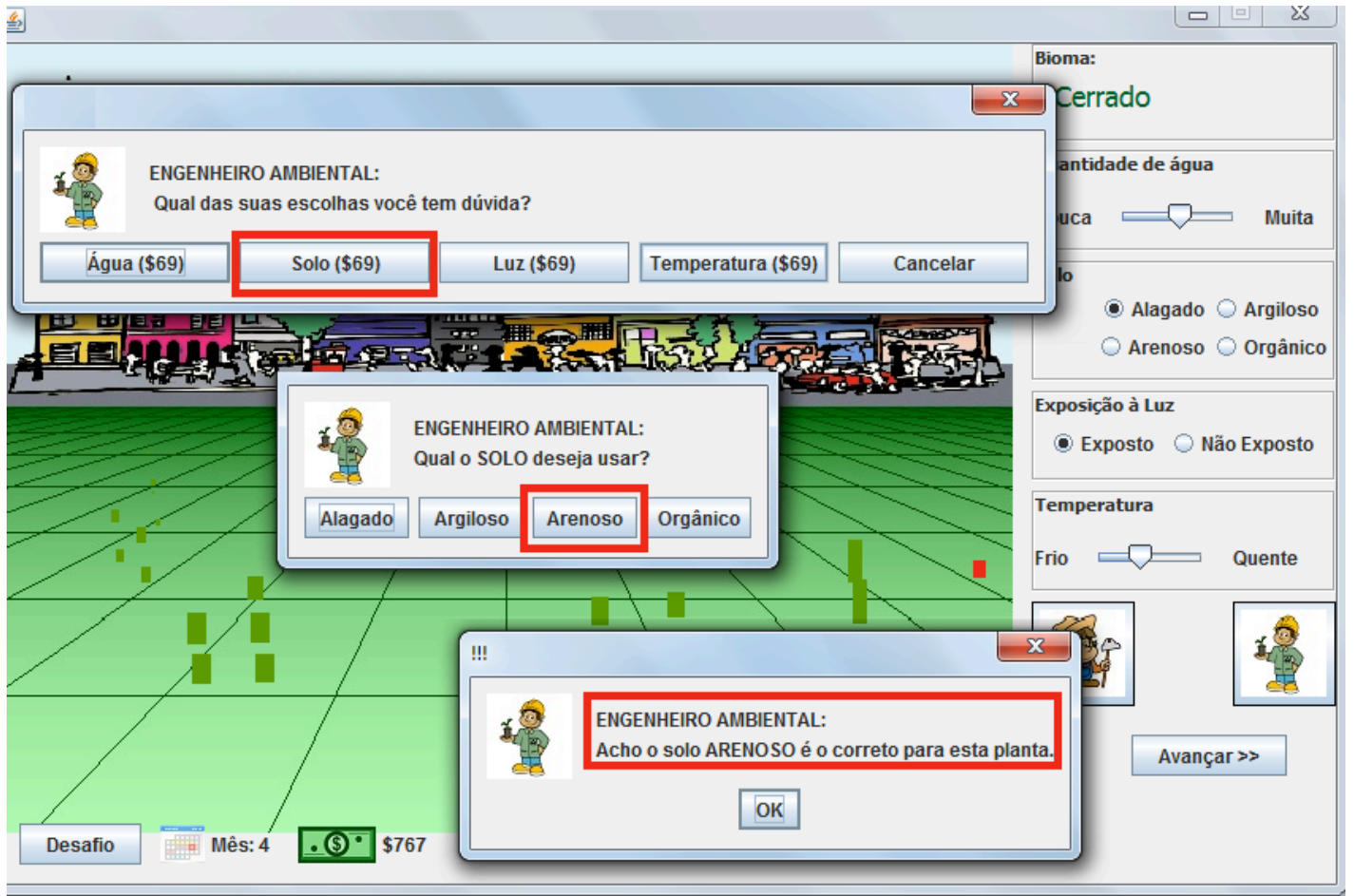

Figura 3. Sequência de passos para dica do Engenheiro ambiental

O jogo conta com uma interface colorida, voltada ao público alvo. As plantas buscam características de plantas reais, nativas do Brasil, e crescem de acordo com o nível de acerto dos parâmetros do usuário. Há aleatoriedade neste crescimento, tanto na posição, quanto ao seu desenvolvimento. Isto se deve ao fato que mesmo em condições 
completamente favoráveis nem todos os indivíduos obrigatoriamente sobreviveriam. O caso contrário também é verdadeiro, pois mesmo em condições adversas, indivíduos mais fortes poderiam sobreviver. Além das informações prestadas pelo fazendeiro e pelo engenheiro, outro fator que demonstra ao jogador como está o reflorestamento é a quantidade de árvores que estão em fase de crescimento.

O fim do jogo pode se processar de diversas maneiras, a saber:

- O jogador consegue reflorestar com bônus: quando o estudante escolhe corretamente todos os parâmetros, ele consegue o melhor resultado no menor tempo possível e recebe um bônus em dinheiro ao terminar o reflorestamento.

- O jogador consegue reflorestar sem bônus: o estudante, provavelmente, necessitou de ajuda do fazendeiro ou engenheiro ambiental, mas consegue atingir o objetivo.

- O jogador escolhe os parâmetros corretos no final, mas não consegue reflorestar, pois as escolhas iniciais não foram boas.

- O dinheiro se encerra, ou seja, várias semanas se passam e o reflorestamento não é concluído.

- O jogador não consegue reflorestar, pois suas escolhas foram erradas e nenhum das plantas consegue sobreviver.

Todos os passos são gravados em um arquivo de log, para posterior análise do professor do andamento da atividade pelo aluno. Além de armazenar as escolhas de cada jogador, cada ajuda selecionada, quando e seu possível impacto, também é descrita no log.

\section{Avaliação Preliminar}

Foi feita uma avaliação preliminar do jogo desenvolvido com objetivo de gerar indicadores iniciais e mesmo apontar direções para os próximos passos da pesquisa. Para isso, o jogo foi utilizado em sala de aula com uma turma do $6^{\circ}$. ano de uma escola pública. O objetivo inicial era avaliar se o jogo permitiria aos alunos consolidar melhor a relação entre os biomas e seus parâmetros. A turma escolhida era composta por 24 alunos e todos eles já haviam estudado os biomas brasileiros anteriormente. Para avaliar o impacto do jogo decidiu-se por fazer um teste inicial do assunto (Pré-teste) com os todos os alunos. Na aula seguinte à atividade todos os alunos desenvolveram um outro teste (pós-teste) sobre o tema. Após o Pré-Teste, a turma foi dividida em dois grupos:

- Grupo A: utilizou o jogo como objeto pedagógico;

- Grupo B: realizou um estudo dirigido sobre o mesmo conteúdo do jogo.

A escolha dos grupos para cada atividade foi feita pela professora de Ciências da turma que buscou equiparar os níveis de aprendizados entre os grupos, ou seja, em ambos havia alunos com bons, médios e maus desempenhos na área de Ciências.

Independente do grupo, a atividade começou com pré-teste. Uma avaliação composta de vinte questões de múltipla-escolha foi aplicada a todos os alunos antes que fossem executadas as tarefas por ambos os grupos. Após a avaliação, a turma foi dividida nos grupos que ficaram em ambientes distintos para realizar a atividade. Os alunos do grupo B ficaram na sala de aula, e os alunos do grupo A foram para o 
laboratório de informática. Na aula seguinte, dois dias depois da atividade descrita, uma avaliação pós-teste com mesmo nível de dificuldade do pré-teste foi aplicado aos alunos dos dois grupos. O objetivo era comparar, preliminarmente, o desempenho dos alunos que utilizaram o jogo e os alunos que fizeram o estudo dirigido e o resultado pode ser visto na Tabela 1.

Tabela 1. Desempenho dos alunos: Pré-teste e Pós-Teste

\begin{tabular}{|l|c|c|c|}
\hline & Pré teste (Máx: 20) & Pós teste (Máx: 20$)$ & Variação \\
\hline Grupo A & $11,00 \pm 2,09$ & $13,60 \pm 3,55$ & $24,74 \% \pm 32,79 \%$ \\
\hline Grupo B & $11,69 \pm 2,83$ & $14,61 \pm 2,87$ & $27,82 \% \pm 21,36 \%$ \\
\hline
\end{tabular}

Se considerarmos os testes aplicados aos alunos, em termos de resultados quantitativos, ambos os métodos promoveram resultados muito parecidos. Os dois grupos obtiveram um aumento médio em sua nota em torno de $25 \%$ levando em conta a diferença entre o pós e o pré teste. O alto desvio padrão, observado em todos os dados estatísticos apresentados, pode ser justificado pela heterogeneidade de níveis entre os alunos de um mesmo grupo. No entanto, apesar de resultados muito próximos, observou-se maior estímulo e engajamento dos que utilizaram a nova tecnologia. A motivação se mostrou de forma clara, através de comentários dos alunos que participaram do grupo que realizou atividade com o jogo. Alguns alunos do Grupo B, ao fim da aula, foram ao laboratório e perguntaram quando poderiam realizar a tarefa. Momento no qual pôde-se observar diversos dos alunos do Grupo A interessados em mostrar para eles o jogo e seu funcionamento.

O interesse e motivação demonstrado pelos alunos foi avaliado pela professora como desejável para o aprendizado. Em sua observação este tipo de comportamento é importante e pode ser utilizado em casos em que o estudante tem problemas de concentração.

Além disso, a professora considerou que a geração dos logs poderia ser uma ferramenta bastante interessante pedagogicamente. Pois, os logs permitiriam aos professores verem as principais dúvidas e erros cometidos pelos alunos, auxiliando-os a definir o planejamento pedagógico e o direcionamento de uma futura atividade didática. É possível verificar com rapidez e eficiência os pontos que devem ser alterados em uma nova atividade, diferentemente do que acontece muitas vezes com recursos como o estudo dirigido. Através dos logs foi possível extrair as seguintes informações a respeito do uso do jogo:

- Controle de alunos que solicitaram mais ou menos ajudas, possibilitando, além do resultado, verificar os que apresentam maior dificuldade e em que ponto específico.

- Se o tipo de ajuda adotada é mais ou menos relevante, pois algumas ajudas podem ser inúteis e de difícil compreensão. Através dos logs, ajudas que não forneçam com frequência resultados melhores podem ser identificadas e modificadas.

- O percurso utilizado pelo estudante é outro fator importante que pode ser observado. 
A princípio a funcionalidade do log foi criada exclusivamente para apoiar o processo de desenvolvimento do software e a avaliação inicial do jogo. Contudo, verificamos ser uma ferramenta didática eficiente para auxílio do professor.

\section{Conclusões}

Este trabalho apresentou uma proposta de jogo voltado para o apoio do Ensino de Ciências para alunos do Ensino Fundamental I e II. Foram discutidos alguns dos desafios vivenciados no processo de desenvolvimento interdisciplinar, considerando os desafios e soluções adotadas. Por fim foi feita uma avaliação preliminar em um contexto real a fim de verificar aspectos práticos da aplicação deste trabalho.

Em termos de modelagem de software educacional, o trabalho gerou contribuições ao apontar que o Modelo de Representação de Apoio ao Aprendizado (MRA) não se mostrou útil para a comunicação entre educadores e desenvolvedores, indicando a necessidade de pesquisas de artefatos que possam auxiliar neste processo.

Além disso, o jogo implementado pôde ser utilizado em um contexto real do ensino de biomas brasileiros, na área de Ciências. Assim, o jogo é um recurso que contribui tanto para a qualidade do Ensino Fundamental, quanto para a pesquisa sobre a tecnologia na sala de aula.

A avaliação sobre o impacto do jogo no ensino, embora inicial, não mostrou melhora de desempenho em relação ao outro método adotado. No entanto, o engajamento dos alunos e a possível aplicação em estudantes com dificuldade de concentração podem ser benefícios interessantes associados ao uso do jogo. Além disso, a possibilidade de acompanhamento dos logs pelo professor mostrou-se um potencial artefato pedagógico.

Os próximos passos nesta pesquisa envolvem ajustes em alguns pontos da interface que se mostraram pouco intuitivos para os alunos durante o uso do jogo. Dentre estes pontos, destacam-se a presença de termos que não foram bem compreendidos pelos alunos e ausência de itens gráficos que destaquem pontos chaves da interação, como o fim do jogo. Além disso, seria interessante incluir elementos gráficos que pudessem tornar a interface do jogo mais atrativa como, por exemplo, as plantas geradas poderiam ser mais parecidas com plantas reais de cada bioma. Os resultados positivos obtidos neste trabalho indicam que seria interessante dar continuidade ao projeto e investir na possibilidade de customização das atividades possíveis pelo professor, oferecendo a este um recurso mais flexível e que possa ser melhor adequado às necessidades específicas de cada turma. Finalmente, para que o uso do log pudesse de fato ser utilizado como pelo professor para analisar dúvidas frequentes, erros cometidos e caminhos de solução adotados pelo aluno seria importante o desenvolvimento de uma ferramenta que analisasse os registros gerados e permitisse diferentes possibilidades de visualização da informação de interesse.

\section{Agradecimentos}

Agradecemos ao Centro Pedagógico/UFMG pela cessão do laboratório de informática para os testes realizados. 


\section{Referências}

Calisto A.; Barbosa, B; Malucelli, A; Silva, C. (2010) "Uma Análise Comparativa entre Jogos Educativos Visando a Criação de um Jogo para Educação Ambiental”, In: XXI Simpósio Brasileiro de Informática na Educação (SBIE), João Pessoa - PB, Brasil.

Kessler, M. C.; de Paula, C. G.; Albé, M. H.; Manzini, N.; Barcellos, C.; Carlson, R.; Marcon, D.; Kehl, C., (2010) "Impulsionando a aprendizagem na universidade por meio de jogos educativos digitais", In: XXI Simpósio Brasileiro de Informática na Educação (SBIE), João Pessoa - PB, Brasil.

Loula, A.C.; Muños, Y.J.; Oliveira, E.S.;. Rocha, P.L.B.; Vargens, M.M.F., Modelagem (2010). Ambiental em um Jogo Eletrônico Educativo. In VIII Simpósio Brasileiro de Games e Entretenimento Digital (SBGAMES), Rio de Janeiro - RJ, Brasil. pág.: $171-180$

Neves, R. G.; Giraffa, L. M. M. (2007) "Pandora: Um jogo de memória configurável”, In: XVIII Simpósio Brasileiro de Informática na Educação (SBIE), São Paulo - SP, Brasil. pág.: 308-311

Paim, M. F. R.; de Paula, B. C., (2009) "Eu, Robô Poeta: Um Jogo para Aprender a Construir Poesias", In: XX Simpósio Brasileiro de Informática na Educação (SBIE), Florianópolis - SC, Brasil. ISSN: 2176-4301

Pietruchinski, H. M; Neto, J.C.; Malucelli, A; Reinehr, S. (2011) "Os jogos educativos no contexto do SBIE: uma revisão sistemática de Literatura”, In: XXII Simpósio Brasileiro de Informática na Educação (SBIE), Aracaju - SE, Brasil. pág.: 476-485

Prates, R. O. ; Figueiredo, R. M. V., (2005) "An Experience with an Enriched Task Model for Educational Software." In: Conference on Human Factors in Computing Systems (CHI), 2005, Portland. CHI 2005 Extended Abstracts. New York: ACM, 2005. p. 1721-1724.

Silva, A. A.; Passerino, L. M, (2007) “A fazenda: Software Educativo para Educação Ambiental”, In: CINTED-UFRGS: Novas tecnologias na Educação Vol. 5, N ${ }^{\circ} 2$.

Silva, B. S.; Barbosa, S. D. J., (2007) "Designing Human-Computer Interaction With MoLIC Diagrams -- A Practical Guide.” In Carlos J. P. de Lucena (ed.), Monografias em Ciência da Computação, 12/07, ISSN 0103-9741.

Silva, M. A. R.; Magalhães, V. M. A.; Anacleto, J. C.,(2010) "O Uso de um Jogo Narrativo Computacional em um Ambiente Escolar", In: XXX Workshop Sobre Informática na Escola (WIE), Belo Horizonte - MG, Brasil. pág.: 1225-1234

Silva, I. K. O.; Morais, M.J.O; (2011) "Desenvolvimento de jogos Educacionais no apoio do processo Ensino-Aprendizagem no Ensino Fundamental”, In: Holos, Ano 27 Vol 5 pág.: 153-164. 